\title{
Morophology and Marphometry of Acnthocephlan, Acathogyrus Acanthogyrus found in Fish Host Catla catla of Hyderabad and Rangareddy Dist.
}

\author{
Dr. G. N. Bhagya Rekha \\ Reader in Zoology. Andhra Mahila Sabha Arts And Science College for Women. Osmania University, Vidyanagar, Hyderabad-- 07
}

\begin{abstract}
Majority of the fishes serve as an intermediate hosts for many parasites, which reduces the food value of the fish as they serve as a potential source of animal protein Catla catla is an edible fish and is a great source of proteins for human being. Fishes in natural waters lodge minimum two kindsof parasites fishes may host either external parasites or internal parasite, external parasites are mainly monogeneas trematodes may be situated on gills and skin internal parasites present in intestine,liver airblader. internal parasites mostly comprises helminth parasites that may be either cestodes or nematodes and acanthocephalans. Helminthes are capable of causing mass mortality of hosts, The present paper deals with the morphology and identification of Acanthocephlan Acanthogyrus acanthogyrus found in host Catla catla collected from defferent ponds of Hyderabad and and Rangareddy districts of Telangana (India) during November, 2000 -October, 2002.
\end{abstract}

Keywords: Morophology, Marphometry, Acnthocephlan, Acathogyrus, Fish host Catla catla

\section{Introduction}

The parasites as organisms occupying the body of another organism called the host. Therefore, parasitism is a form of animal association and more so, an ecological relationship between two heterospecific organisms. Parasites are very common throughout the world. Parasites affect growth, health, and survival of fish and parasitic diseases can spread rapidly causing gross mortalities. Parasites attack their fish host on gills, dermis, and internal organs and their presence in fish depends largely on their habitats, life cycle of parasites. Parasitic load of fish in particular aquatic system can be used as an indicator of environmental stress. The correct identification of helminthes is necessary before any inquiry is made into their ecology, host-parasite relations, physiology, biochemistry, pathology, immunology so on and so forth for proper growth of helminthology as a discipline.

\section{Material \& Methods}

The fishes harbour helminth parasites on the skin, fins and gills (monogeneans), in the digestive tract (digeneans, aspidogastreans, cestodes, nematodes and acanthocephalans). The live fish after spinal severance is laid on a table and scissors are introduced into the anus. Median incision is made from anus towards head up to the pectoral fins, The different regions of gut is placed in a large petridish containing $0.85 \%$ of saline and parasites were collected

To ensure specimens adequate for accurate study of proboscis characteristics and internal anatomy, living specimens of acanthocephalans were put in a cavity block containing (hypotonic) tap water and refrigerated for 12-24 hrs. They were then fixed in glyceralcohol or AFA solution at room temperature. The semi-permanent whole mount preparation of formalin fixed specimens of Acanthocephalans are made using glycerin or glycerin jelly. The permanent whole mounts of acanthocephalans were prepared following alum carmine stain procedure to obtain details of reproductive system (Lucky, 1977).

\section{Measurement, Illustrations}

Terminology

and

Measurement of the helminth papasites is recorded in millimeters from semi -permanent and permanent whole mount preparations with the aid of calibrated ocular micrometer and camera lucida profiles; they were expressed as minimum and maximum ranges. The method of recording measurements and terminology followed was as suggested by Amin and Williams (1983) to the acanthocephalans. Acantholehalans collected here were (Acanthogyru acanthogyrus)

Acanthocephala Koelreuther, 1771

Eoacanthocephala Van Cleave, 1936

Gyracanthocephala Van Cleave, 1936

Quadrigyridae Van Cleave, 1920

(= Acanthogyridae Thapar, 1927;

$=$ Pallisentidae Van Cleave, 1928)

Pallisentinae Van Cleave, 1928

Acanthogyrus Thapar, 1927

( = Acanthosentis Verma et Datta, 1929)

A (A.) acanthogyrus Thapar, 1927

(plateI.1; Figs. $1 \& 2$; Plate I.2; Figs. $1 \& 2$ )

Thapar in the year 1927 erected the genus Acanthogyrus with the type species $A$. acanthogyrus parasitic in the intestine of rohu, Labeo rohita from Lucknow, India. To accommodate it he established a new family Acanthogyridae and Order Acanthogyridea. Datta and Poddar (1935) recorded the same specimens from the intestines of catla, Catla catla from Calcutta, India.

Yamaguti (1963) reported in the foot notes to the genus Acanthogyrus, the opinion of Dollfus and Golvan (1956) that in Acanthogyrus, Thapar, Datta and Poddar probably misinterpreted the cement gland and cement reservoir as two cement glands or two lobes of one gland. Further, he 


\section{International Journal of Science and Research (IJSR) \\ ISSN (Online): 2319-7064 \\ Index Copernicus Value (2013): 6.14 | Impact Factor (2015): 6.391}

suggested to separate them as two independent genera Acanthogyrus Thapar, 1927 and Acanthosentis Verma et Datta, 1929 against synonymization of latter to the former by Dollfus \& Golvan, provisionally until a restudy of them is made.

Golvan (1959) relegated the two genera, Acanthogyrus and Acanthosentis and included them as subgenera within Acanthogyrus based on the number of proboscis hooks 18 (3 circles of 6 hooks each) in Acanthosentis and 24 (3 circles of 8 hooks each) in Acanthogyrus. This arrangement has been accepted by the most systematists (Amin, 1985, 1987). Amin and Hendrix (1999) and Amin (2005) did not agree Golvan's (1994) elevating Acanthosentis back to generic status without justification and they retained the sub-generic classification of the genus Acanthogyrus Thapar, 1927. The present researcher follows it for the specimens collected from the intestine of $C$. catla.

\section{Description}

Specimens studied and measured (10 each of male and female worms)

\section{Male worms}

The male worms are shorter than the female worms. The body of the worms is elongated and club-shaped and measures $3.2-3.58 \mathrm{~mm}$ in total length and $0.51-0.87 \mathrm{~mm}$ in the greatest diameter acquired below the proboscis sheath or receptacle.The eversible and retractable proboscis or introvert (Plate I. fig.1) is sub globular in shape; it measures $0.11 \mathrm{~mm} \times 0.09 \mathrm{~mm}$. It is armed with three rows of eight hooks each. The hooks of first row to third row tend to decrease in size. They consist of a horizontal handle (root), posteriorly directed guard and re curved and tapering blade. The roots of the hooks embed in the wall of proboscis and the blades are free over the proboscis. There is a short unarmed neck behind the proboscis. The neck and proboscis on retraction enter into a closed sac-like muscular proboscis receptacle; its wall is simple and single layered. On either sides of proboscis, its basal inner hypodermis invaginates into the pseudocoelom as lemniscus; the two lemnisci hang free in the pseudocoelum for the greater part of their length. They are almost equal in length and extend up to a length of $0.032-0.045 \mathrm{~mm}$ from the anterior end

The trunk (meta-soma) consists of transverse rows of several spines up to mid length of the body or slightly beyond and one or two rows with only two spines at the posterior end. There are seven rows of anterior (collar) spines and 17-22 rows of posterior (trunk) spines with a hook-free zone $(0.09$ $\mathrm{mm}$ in length) in between. The spines are triangular with broad base embedded in the body wall and pointed end directed posteriorly. The number of spines in each row tends to decrease posteriorly; they measure $0.009-0.012 \mathrm{~mm}$ in length. At the posterior end, the worms are broadly rounded.

There are two distinct testes post-equatorially (Plate I-1;) They are slightly elongated and arranged in tandem in the ligament sac. The interior testis measures $0.021 \mathrm{~mm} \times 0.016$ $\mathrm{mm}$, while the posterior one measures $0.018 \mathrm{~mm} \times 0.016$ $\mathrm{mm}$. From each testis arises a narrow sperm duct or vas efferens; they run caudad and unite together to form vas deferens. It forms seminal vesicle prior to joining with the cement ducts. Posterior to the posterior testis is a single slightly elongated syncytial cement gland containing 3-4 nuclei. It measures $0.015 \mathrm{~mm}$ in length and $0.008 \mathrm{~mm}$ in width. A spherical cement reservoir measuring $0.006 \mathrm{~mm}$ in diameter lies behind the cement gland. From it, a pair of long cement ducts run posteriorly along with the vas deferens; they enter separately into the penis. The vas deferens and cement ducts are enclosed by genital sheath. The penis opens into the male copulatory bursa. Arising from the bursa and extending up to the cement reservoir is a long blind muscular sac called saefftigen's pouch. It measures $0.25 \mathrm{~mm}$ in length. When it contracts fluid is forced into the lacunar spaces of the bursa and it assists in its eversion.

\section{Female worms}

The female worms are longer and stouter than the male worms; they measure $4.57-8.6 \mathrm{~mm}$ in length and $0.76-$ $1.24 \mathrm{~mm}$ in greatest diameter attained pre-equatorially below the proboscis receptacle. The proboscis (plate I-2; fig.1) measures $0.09-0.15 \mathrm{~mm} \times 0.09-0.11 \mathrm{~mm}$. The armature of proboscis is identical to those of male worms; the hooks of the first to third row measure $0.071 \mathrm{~mm}, 0.059$ $\mathrm{mm}$, and $0.048 \mathrm{~mm}$ in length respectively. The proboscis receptacle wall is made of single layer. Two lemnisci, running one on either side of the proboscis receptacle from the region between base of neck and collar extend beyond the proboscis receptacle; they measure $0.036-0.045 \mathrm{~mm}$ in length from the anterior end.

The trunk spination of female worms is similar to those of male worms. However, collar spines, trunk spines, their number of rows, and number of spines in rows are slightly more in female worms. The spines measures $0.01-0.013$ $\mathrm{mm}$ in length. Posterior end of female worms is broadly rounded.

In mature female worms, the ovary is in the form of a number of ovarian balls suspended in the dorsal ligament sac. They measure $0.033-0.035 \mathrm{~mm}$ in diameter. The dorsal ligament sac encloses a muscular uterine bell, the latter collects mature eggs from the former. The uterine bell measuring $0.076 \mathrm{~mm}$ in length, in turn opens posteriorly into a long muscular uterus; it measures $0.29-0.39 \mathrm{~mm}$ in length and $0.009-0.01 \mathrm{~mm}$ in diameter. It enters posteriorly into vagina measuring $0.043-0.07 \mathrm{~min}$ in length and $0.03-$ $0.032 \mathrm{~mm}$ in diameter and opens out as eventually female genital pore. The uterus and vagina are enclosed in the ventral ligament sac.

The uterine bell has at its base a selector apparatus. It allows mature eggs to pass through into the uterus and vagina and out through the genital pore and returns immature eggs into the dorsal ligament sac for further maturation in it. After copulation, the cement gland secretion forms a post copulatory cap or plug in the female genital pore to prevent further insemination.

Records :Acanthogyrus (Acanthogyrus) acanthogyrus Thapar, 1927 


\section{International Journal of Science and Research (IJSR) \\ ISSN (Online): 2319-7064}

Index Copernicus Value (2013): 6.14 | Impact Factor (2015): 6.391

Location; intestine: Host: Catla catla : Dist : Dhaka

: Ahmed and Begum 1978 (Dhaka); Ahmed and Rouf 1981

(Dhaka); Ahmed 1981 (Dhaka)
Remarks: parasites are mostly host specific in present study (A.) acanthogyrus Thapar, 1927 is a lone endohelminth recorded from the intestines of $C$. catla in present study collected from the ponds and water bodies of Hyderabad and Ranga Reddy districts of A.P.
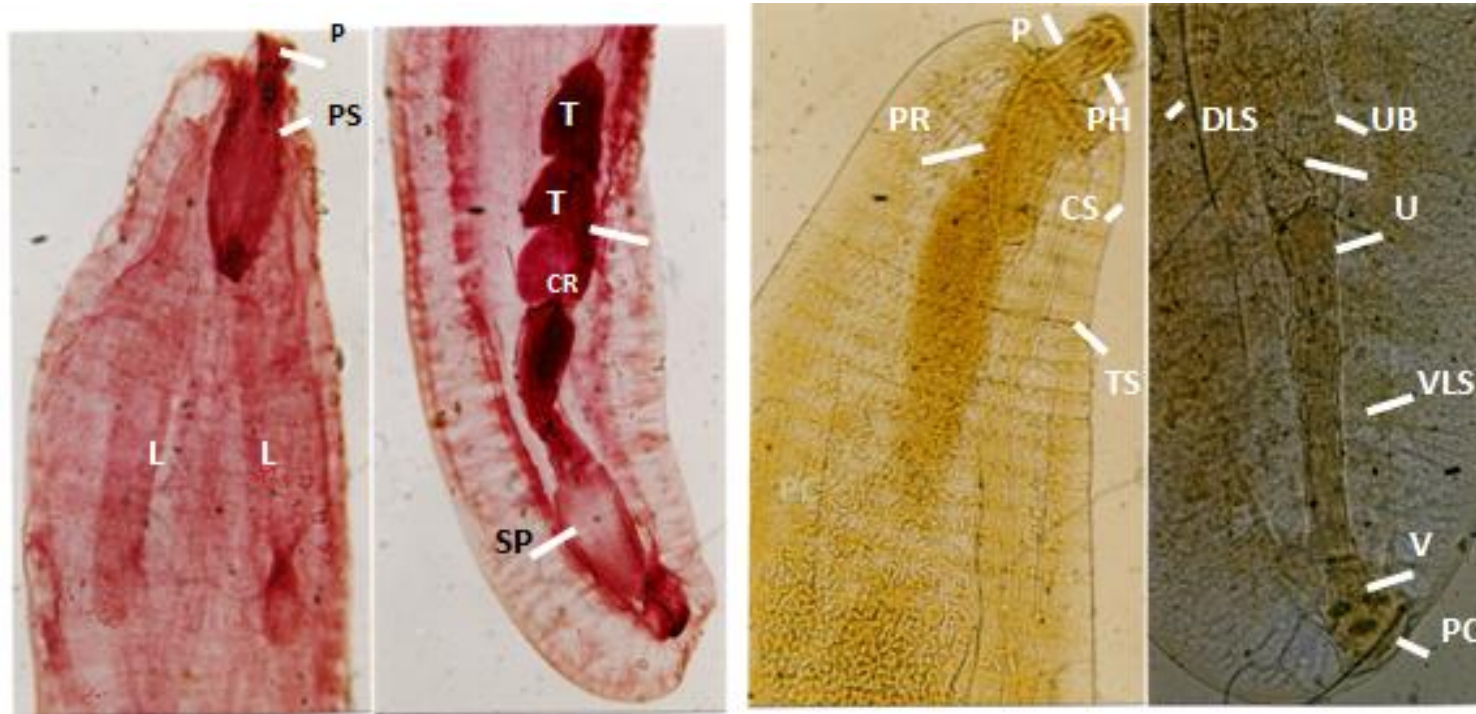

PLATE I.1 : A.(A). acanthogyrus (alum carmine Staine ) PLATE I.2 : A.(A). acanthogyrus (Jain, 1962)

Figure 1: Anterior end -proboscis, proboscis sheet, lemnisci. Fig. 1.Anterior end of female worm proboscis, its hooks Figure 2: Posterior end of male worm reproductive organs Fig. 2. Posterior end of female worm reproductive systems

CR-Cement reservoir; CG-Cement gland; CS-Collar spines; DLS-Dorsal ligament Sac; V-Vagina L-Lemnisci; P-Proboscis; PS-Proboscis sheath; PC- Postcoupulation Cap (plug); PH-Proboscis hooks SP-Saeftigens pouch; T-testis PR-Proboscis receptacle, SA-selector apparatus

VLS-Ventral ligament Sac; TS-Trunk spines U-Uterus; UB-Uterine bulb

\section{References}

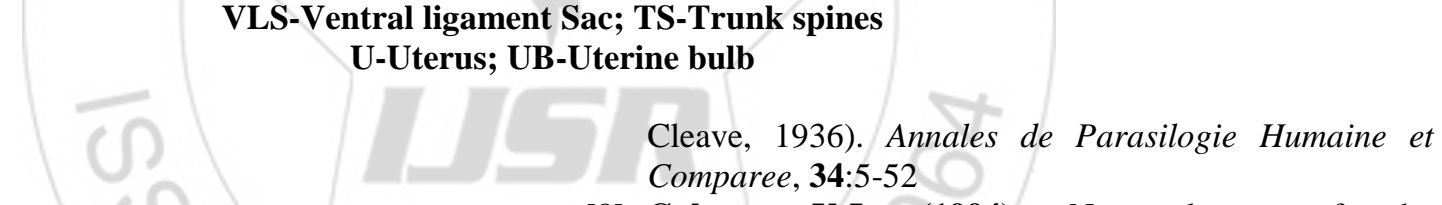

[1] Amin, O.M. (1985). Classification. In Biology of the acanthocephalan. (Eds.) D.W.T. Crompton \& B.B. Nickol, Cambridge : Cambridge University Press, pp.27-72.

[2] Amin, O.M. (1987). Key to the Families and subfamilies of Acanthocephala, with the erection of a new class (Polyacanthocephala) and a new Order (polyacan thorhynchida). J.Parasitol., 77 : 1216-1219.

[3] Amin, O.M. \& Hendrix, S.S. (1999). Acanthocephala of Cichlids (Pisces) in Lake Malawi, Africa with a description of Acanthogynus (Acanthosentis) malawiensis sp. n. (Quadrigyridae) from Labeo cylindricus Peters, 1852 (Cyprinidae), J. Helninthol. Soc. Wash, 66 : 47-55.

[4] Datta, M.N. \& Podder, T.N. (1935). Acanthocaphalan parasites of certain fishes from Calcutta,

[5] Amin, O.M. (2005). Occurrence of the subgenus Acanthosentis Verma \& Datta, 1929 (Acanthocephala : quadrigyniclae) in Japan, with the description of acanthogyrus (Acanthosentis) alternatspinus n.sp. and A. (A.) para receptaclis $\mathrm{n}$. $\mathrm{sp}$. from Lake Biwa drainage fishes and a key to the species of the subgenus. Systematic parasitol, 60 : 125-

[6] Rec. Ind. Mus., 37 : 231-236

[7] Golvan, Y.J.(1959). Le Phylum des Acanthocephala. Deuxieme note, La classe de Eoacanthocephala (Van
[8] Golvan, Y.J. (1994). Nomenclature of the Acanthocephala. Research and Reviews in Parasitology, 54 : 135-205.

[9] Thapar, G.S. (1927). On Acanthogyrus n.g. from the intestine of the Indian fish Labeo rohita with a note on the classification of the Acanthocephala. J. Helminthol., 5: 109-120.

[10] Yamaguti, S. (1963b). Systema Helminthum, vol.5, Acanthocephala. Inter- science publishers, a division of John Wiley \& Sons, New York \& London VII + 423.

Disclaimer: This research paper is original neither it is published in full nor in parts in any journal. 